\title{
Automated reconstruction of rainfall events responsible for shallow landslides
}

\author{
G. Vessia ${ }^{1,2}$, M. Parise ${ }^{2}$, M. T. Brunetti ${ }^{3,4}$, S. Peruccacci ${ }^{3}$, M. Rossi ${ }^{3,4}$, C. Vennari ${ }^{2}$, and F. Guzzetti ${ }^{3}$ \\ ${ }^{1}$ Department of Engineering and Geology, University "G. d'Annunzio" of Chieti-Pescara, Via dei Vestini 31, 66031, \\ Chieti Scalo $(\mathrm{CH})$, Italy \\ ${ }^{2}$ Institute of Research for Hydrogeological Protection, National Research Council, Via Amendola 122 I, 70126 Bari, Italy \\ ${ }^{3}$ Institute of Research for Hydrogeological Protection, National Research Council, Via Madonna Alta 126, \\ 06128 Perugia, Italy \\ ${ }^{4}$ Department of Earth Science, University of Perugia, Piazza dell'Università 1, 06123 Perugia, Italy
}

Correspondence to: G. Vessia (g.vessia@unich.it)

Received: 21 February 2014 - Published in Nat. Hazards Earth Syst. Sci. Discuss.: 25 April 2014

Revised: - - Accepted: 3 August 2014 - Published: 10 September 2014

\begin{abstract}
Over the last 40 years, many contributions have identified empirical rainfall thresholds (e.g. rainfall intensity $(I)$ vs. rainfall duration $(D)$, cumulated rainfall vs. rainfall duration (ED), cumulated rainfall vs. rainfall intensity (EI)) for the possible initiation of shallow landslides, based on local and global inventories. Although different methods to trace the threshold curves have been proposed and discussed in literature, a systematic study to develop an automated procedure to select the rainfall event responsible for the landslide occurrence has only rarely been addressed. Objective criteria for estimating the rainfall responsible for the landslide occurrence play a prominent role on the threshold values. In this paper, two criteria for the identification of the effective rainfall events are presented. The first criterion is based on the analysis of the time series of rainfall mean intensity values over 1 month preceding the landslide occurrence. The second criterion is based on the analysis of the trend in the time function of the cumulated mean intensity series calculated from the rainfall records measured through rain gauges. The two criteria have been implemented in an automated procedure that is written in the $\mathrm{R}$ language. A sample of 100 shallow landslides collected in Italy from 2002 to 2012 was used to calibrate the procedure. The cumulated event rainfall $(E)$ and duration $(D)$ of rainfall events that triggered the documented landslides are calculated through the new procedure and are fitted with power law in the $D, E$ diagram. The results are discussed by comparing the $D, E$ pairs calculated by the automated procedure and the ones by the expert method.
\end{abstract}

\section{Introduction}

Rainfall is a known trigger of landslides, and its role in initiating slope instability depends on the local geological, morphological and hydrological conditions, vegetation cover, and their complex interactions (De Vita and Reichenbach, 1998; Guzzetti, 1998; Wieczorek and Guzzetti, 2000). A common approach to relate rainfall measurements to the occurrence of landslides is to use empirical rainfall thresholds (e.g. Caine, 1980; Innes, 1983; Crosta and Frattini, 2000; Aleotti, 2004; Cannon and Gartner, 2005; Guzzetti et al., 2007, 2008). To determine the thresholds, information on (i) the geographical location, (ii) the occurrence time of the landslide, and (iii) the amount of rainfall that presumably caused the slope instability is necessary. Location and time of landslide occurrence are obtained from chronicles, historical archives, technical reports, aerial photography, satellite imagery, and time series of historical landslides. Information on rainfall measurements, including rainfall duration $(D)$ and cumulated event rainfall $(E)$, considered responsible for the slope failures is obtained typically from single rain gauges or from networks of rain gauges (Aleotti, 2004; Guzzetti et al., 2007), although examples exist of the use of satellite-derived rainfall estimates (Hong et al., 2006; Bach Kirschbaum et al., 2009).

A problem with the definition of empirical rainfall thresholds for possible landslide occurrence consists in the subjectivity inherent to the determination of the rainfall conditions that have resulted in landslides (Aleotti, 2004; Guzzetti 
et al., 2007; Brunetti et al., 2010; Melillo et al., 2014). In an attempt to overcome this limitation, we present a procedure - and an associated code written in R, the free software environment for statistical computing and graphics (http: //www.r-project.org/) - for the objective (i.e. reproducible) determination of the rainfall conditions that triggered the documented landslides. The procedure explores a record of rainfall measurements and determines the rainfall conditions (i.e. the $D$, in hours, and the $E$, in millimetres), considered responsible for the failure, using information on the landslide occurrence time. The procedure does not consider the environmental (i.e. geological, morphological, hydrological, meteorological or climatic) conditions under which the landslide occurred. We tested the procedure using a sample of 100 rainfall events that initiated 100 single landslides in Italy in the 11-year period from 2002 to 2012.

\section{Background}

Guzzetti et al. $(2007,2008)$ performed a critical review of the literature on empirical rainfall thresholds for possible landslide occurrence, pointing out inconsistencies in the use of terms, in the rainfall metrics, and in the methods used to determine the thresholds. Guzzetti et al. (2007) grouped the approaches used to determine the thresholds into three broad categories: (i) approaches that use precipitation measurements obtained for rainfall events that have resulted (or have not resulted) in landslides, (ii) approaches that consider the antecedent rainfall conditions, and (iii) other approaches that use combinations of indexes representative for both event and antecedent rainfalls calibrated on different case studies. The first two types of approaches are discussed hereafter.

Approaches of the first type solely consider the event rainfall (i.e. the rainfall fallen during the rainfall-triggering event), and do not take into account the antecedent rainfall conditions. Moreover, they do not suggest any general rules to identify the rainfall responsible for landslide initiation. These studies focus on empirical evidence drawn from specific sites without attempting to derive criteria to be used elsewhere. Many of these are the contributions in this study, but only a few of them are cited herein. For instance, Onodera et al. (1974) showed that the number of landslides in Japan increased significantly when the cumulated event rainfall exceeded 150 to $200 \mathrm{~mm}$, and the rainfall mean intensity exceeded 20 to $30 \mathrm{~mm} \mathrm{~h}^{-1}$. Oberstelehn (1976) found that about $250 \mathrm{~mm}$ of cumulated event rainfall were necessary to trigger landslides in the San Benito County, California. Nilsen et al. (1976), working in the Alameda County, California, showed that landslides occurred when the cumulated event rainfall exceeded $180 \mathrm{~mm}$. Brand et al. (1984) suggested that landslides in Hong Kong were triggered by rainfall events exceeding $175 \mathrm{~mm}$ in $24 \mathrm{~h}$, or $70 \mathrm{~mm}$ in $1 \mathrm{~h}$.

Approaches of the second type take into account the antecedent rainfall conditions, i.e. the precipitation fallen in the period that precedes the rainfall event directly responsible for the landslide. These approaches are based on the identification of the length for the antecedent period that can vary from a few hours (Larsen and Simon, 1993; Wilson and Wieczorek, 1995) to several months (Govi et al., 1985; Calcaterra et al., 2000; Cardinali et al., 2006), depending on e.g. the rainfall history, the local physiography, the climatic conditions, and heuristic knowledge. Lumb (1975) suggested that the antecedent rainfall cumulated in a period of 15 days, combined with the rainfall intensity for the event, was responsible for the initiation of landslides in Hong Kong. Campbell (1975), working in southern California, proposed a combination of the cumulated rainfall necessary to bring the soil to field capacity, and an event rainfall intensity exceeding the minimum rate of surface infiltration to exceed soil drainage, so as to trigger soil slips in his study area. Govi et al. (1985), working in Piedmont, NW Italy, determined that a 60-day antecedent rainfall exceeding $140 \mathrm{~mm}$ was needed to trigger landslides, and that a total precipitation (i.e. the antecedent plus the event rainfall) exceeding $300 \mathrm{~mm}$ was likely to initiate the landslides. Ng and Shi (1998), working in Hong Kong, indicated a critical duration of the antecedent rainfall between 3 and 7 days. Pasuto and Silvano (1998), working in the Cordevole River basin, NE Italy, established a 15-day period of cumulated rainfall for landslide occurrence, with the peak rainfall occurring 2 days before the failure. Rahardjo et al. (2001), working in Singapore, suggested 5 days of antecedent rainfall as the critical duration for landslide occurrence. Cardinali et al. (2006) established that landslides in SW Umbria, Italy, are likely to occur when the antecedent rainfall exceeds $590 \mathrm{~mm}$ in a 3-month period, or $700 \mathrm{~mm}$ in a 4-month period. Glade et al. (2000), working in New Zealand, proposed a combined model that considered the rainfall fallen during the day of the landslide and the antecedent rainfall in a period of 10 days before the landslide. The antecedent rainfall was weighted on the temporal distance from the day of the landslide.

Guzzetti et al. (2007) pointed out that, regardless of the adopted approach, a common problem for many investigations is the lack of unambiguous criteria for the identification of the duration of the rainfall event considered responsible for the landslide occurrence. Uncertainty about the duration of the rainfall affects the measurement of the cumulated event rainfall, and the computation of the rainfall mean intensity. Only a few authors have specified clear criteria to determine the duration of the rainfall event responsible for landslide occurrence. Aleotti (2004), working in Piedmont, NW Italy, proposed using the rainfall duration between the time when the cumulated rainfall curve exhibits an abrupt (distinct) increase (i.e. significantly augmented rainfall intensity) and the time when the landslide occurred or was reported. A disadvantage of this approach is that, although the criteria for the definition of the event and the computation of the rainfall metrics were specified, the criteria were decided for site-specific conditions and no attempts were performed 
to calibrate them under diverse climatic and geographic conditions. Thus, no general rules are drawn up elsewhere for predicting the rainfall conditions for landslide initiation. In an attempt to overcome - or to mitigate - this problem, we propose an objective procedure for the identification of the $D$ of rainfall events responsible for landslides. The automated procedure is based on a set of criteria that are similar to those used by Brunetti et al. (2010) to manually determine the rainfall conditions that have resulted in landslides in Italy (hereafter named the expert method). In Sect. 3, the expert method is recalled and described. Section 4 illustrates the automated procedure, which reconstructs automatically the rainfall $(D$, $E$ ) conditions that have resulted in landslides. Section 5 describes a case study. Finally, Sect. 6 discusses results from the automated procedure and the expert method in terms of the $(D, E)$ pairs and the empirical mean rainfall threshold curves.

\section{The expert method}

Brunetti et al. (2010), working in Italy, proposed a heuristic, expert method that exploits landslide and rainfall information for determining the $D$ (in hours), and the rainfall mean intensity $I$ (in $\mathrm{mm} \mathrm{h}^{-1}$ ) that is presumably responsible for the observed landslides.

The information on the geographical location of the landslide is used to select the rain gauge that likely measured the rainfall responsible for the slope failure (representative rain gauge). Criteria for selecting the representative rain gauge include (i) its geographical distance from the landslide, (ii) the difference between its elevation and the landslide elevation, and (iii) the general physiographical settings in the areas where the landslide and the rain gauge are located. When a representative rain gauge is selected, the method uses the known or inferred time of the landslide to determine the "end time" $T_{\mathrm{E}}$ of the rainfall event responsible for the failure. The end time is taken to coincide with the hour, the end of the period of the day (e.g. night, morning, noon, afternoon, evening), or the end of the day when the landslide occurred, depending on the temporal accuracy associated with each landslide information (Brunetti et al., 2010). For shallow landslides that failed after the end of the rainfall event (a rare but possible situation, e.g. Guzzetti et al., 2004), the end time is taken to coincide with the end of the rainfall event. The selection of the "start time" $\left(T_{\mathrm{S}}\right)$ of the rainfall event is more difficult, and requires additional selection criteria. Rainfall is not necessarily continuous, and, consequently, it results in being difficult to separate successive rainfall events. A typical rainfall event consists of periods of rain separated by dry periods without rain. Some of the dry periods are short (of the order of hours), and do not affect the identification of the rainfall event. When the dry periods are long, their effect can be relevant, and the preceding and the following rainfall measurements are considered as distinct rainfall events. In the heuristic method, a specific criterion determines the minimum length of the dry period to separate two rainfall events. Decision on the length of the dry period depends primarily on the local climatic conditions. Brunetti et al. (2010) considered a 2-day $(48 \mathrm{~h})$ period without rainfall (dry period) to separate rainfall events during the late spring and summer period (May-September), and a 4-day (96h) period for the other seasons (October-April). Peruccacci et al. (2012) adopted the same criteria to identify rainfall events with landslides in the Abruzzo, Marche and Umbria regions, central Italy. Vennari et al. (2014), working in Calabria, southern Italy, used a 2-day period without rainfall between April and October, and a 4-day period between November and March to separate successive rainfall events.

Once the $T_{\mathrm{S}}$ and the end time ( $\left.T_{\mathrm{E}}\right)$ of a rainfall event are identified, the duration of the event is $D=T_{\mathrm{E}}-T_{\mathrm{S}}$ (in hours) and the corresponding $E$ is the sum of the rainfall fallen in the time interval $D$ (in millimetres). The rainfall mean intensity is $I=E / D\left(\right.$ in $\left.\mathrm{mm} \mathrm{h}^{-1}\right)$.

The heuristic, expert method is apparently straightforward to apply, but it involves a high subjectivity. Further, results of a long-term project for the collection of information on the rainfall conditions that have resulted in landslides in Italy (Gariano et al., 2012) indicate that it is difficult for an investigator to apply the established criteria rigorously, and to be consistent with the identification of the rainfall events. The higher the number of investigators, the higher the subjectivity, which makes it difficult to prepare accurate catalogues of rainfall events with landslides for large geographical areas. Moreover, the heuristic reconstruction of rainfall events is a labour-intensive, time-consuming and error-prone activity that limits the definition of reliable rainfall thresholds for the possible occurrence of landslides.

\section{The automated procedure}

The automated procedure reproduces the actions performed by an investigator who examines a record of hourly rainfall measurements searching for a rainfall period responsible for the initiation of a documented landslide. To identify the rainfall period in the record, the investigator (and the procedure) needs information on the $T_{\mathrm{S}}$ and the $T_{\mathrm{E}}$ of the rainfall event. As for the expert method, the $T_{\mathrm{E}}$ coincides with the landslide occurrence time, most commonly obtained from chronicles, anecdotal information, or from a catalogue of landslide events (Brunetti et al., 2010). Again, when the landslide occurs after the end of the rainfall period, the $T_{\mathrm{E}}$ coincides with the end of the rainfall period. In this work, we define a rainfall event as an ensemble of consecutive rainfall and dry periods responsible for the occurrence of a known landslide. The length of the dry periods that separate two successive rainfall events $\left(\Delta T_{\mathrm{D}}\right)$ can vary depending on seasonal or climatic conditions (Peruccacci et al., 2012). To cope with this variability, the procedure uses different lengths of the dry 


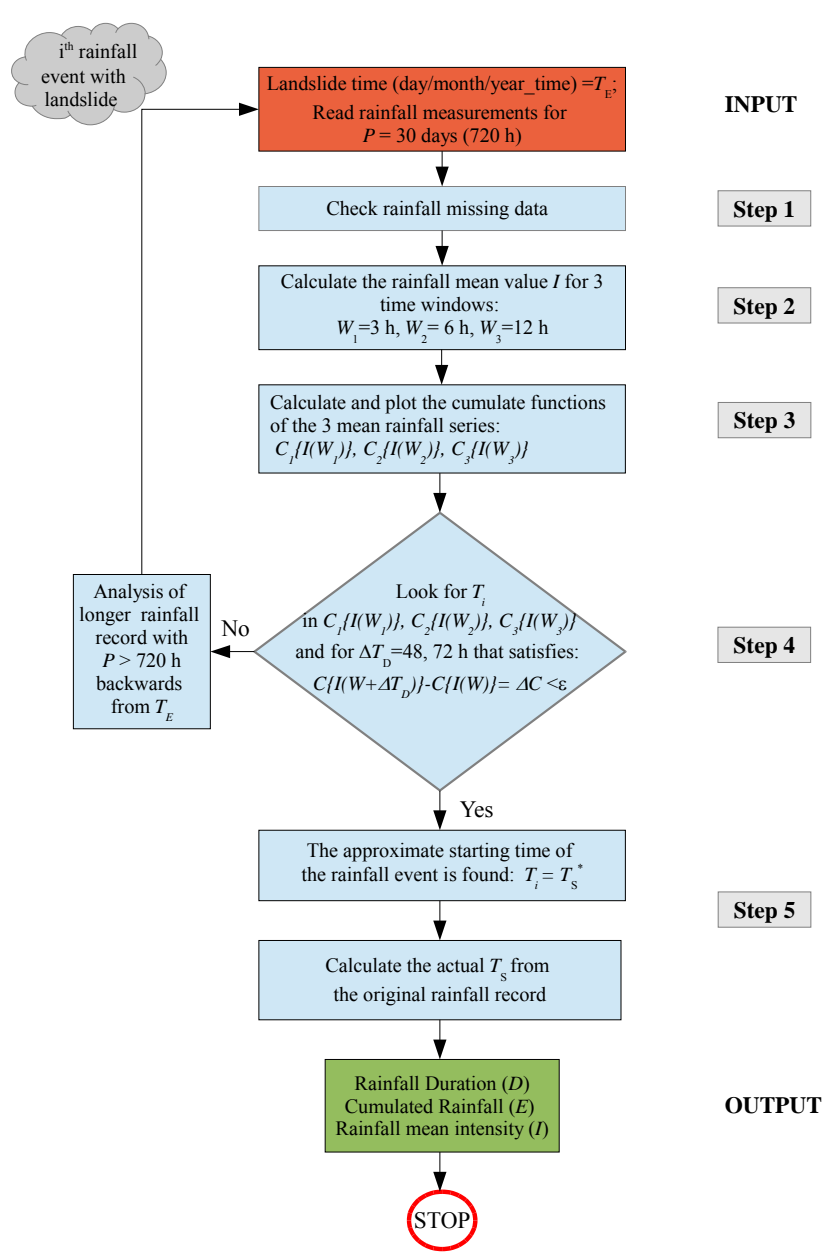

Figure 1. Flowchart of the automated procedure summarized into five steps, and two input and output steps.

periods. We test the automated procedure setting two dry period lengths (i.e. $\Delta T_{\mathrm{D}}=48 \mathrm{~h}$ and $\Delta T_{\mathrm{D}}=72 \mathrm{~h}$ ). These values can be changed according to the local seasonal or climatic conditions.

In the following, we explain the new procedure in five steps. Figure 1 shows the logical framework for the procedure.

\subsection{Data input and preliminary processing}

At the input stage, the landslide occurrence $T_{\mathrm{E}}$ is read (by the automated procedure) together with the rainfall measurements recorded by the representative rain gauge, for a time span $(P)$ equal to 30 days $(720 \mathrm{~h})$ before $T_{\mathrm{E}}$. The $P$ value is a preliminary choice that the operator can change according to the climatic conditions.

In step 1, the record of hourly rainfall measurements (Fig. 2) is entered and checked by the procedure. As a matter of fact, before proceeding with the identification of the rainfall event $T_{\mathrm{S}}$, the procedure identifies possible "missing

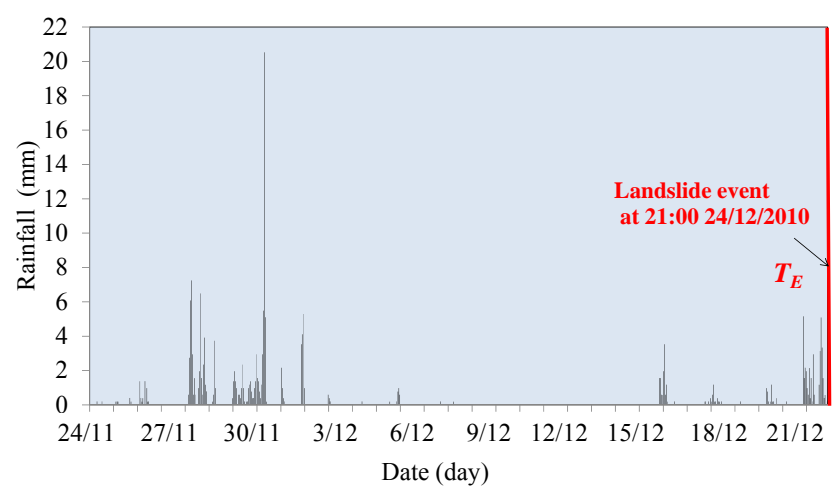

Figure 2. The rainfall record read by the automated procedure (input step), for which the time length is 30 days before the date of the landslide.

data" in the record. These missing data, hidden in the rainfall records, correspond to temporary rain gauges out of service and can last for many hours. They can be a source of errors in the identification of the $(D, E)$ condition responsible for the failure. Hence, if these are detected, the procedure interrupts and the reconstruction of that rainfall event is skipped.

\subsection{Calculation of cumulated mean rainfall intensities}

In step 2, starting from $T_{\mathrm{E}}$ and moving backwards in time, the procedure calculates the rainfall mean intensity $(I)$ within non-overlapping time windows $(W s)$ of variable fixed length. Here, we use $W_{1}=3 \mathrm{~h}, W_{2}=6 \mathrm{~h}$, and $W_{3}=12 \mathrm{~h}$, but the window length can be changed according to specific requirements. The procedure calculates three time series of rainfall mean intensity values: $\left\{I\left(W_{1}\right)\right\},\left\{I\left(W_{2}\right)\right\}$, and $\left\{I\left(W_{3}\right)\right\}$. Each intensity value is assigned to the end of the $W$. Hence, the intensity series show a zero value at $T_{\mathrm{E}}$ and the first intensity value at $T=W$. Figures $3 \mathrm{a}$, $\mathrm{d}$, and $\mathrm{f}$ show the preceding steps. Intensity series are useful to highlight the rainy pattern by smoothing the small amount of rain that is not relevant for the landslide initiation. The number of computed values $(N)$ in the three time series decreases as the length of the time window increases; i.e. $N_{1}=240, N_{2}=120$, and $N_{3}=60$ for $W_{1}, W_{2}$ and $W_{3}$, respectively.

In step 3, for each $W$, the procedure cumulates the calculated rainfall mean intensity values $(C)$, and outputs three cumulated time series of mean rainfall intensity values: $C_{1}\left\{I\left(W_{1}\right)\right\}, C_{2}\left\{I\left(W_{2}\right)\right\}$ and $C_{3}\left\{I\left(W_{3}\right)\right\}$ (Fig. 3b, c, e). Use of $W s$ of different lengths is performed in an attempt to capture differences in the rainfall temporal pattern responsible for the landslide. For instance, for a rainfall characterized by short, rainy, and dry periods, a short window of 3 hours highlights the rainfall conditions that caused the landslide well, whereas, for a rainfall with long rainy period separated by long dry periods, a window of $12 \mathrm{~h}$ is more suited to highlighting the rainfall conditions that initiated the failure. 

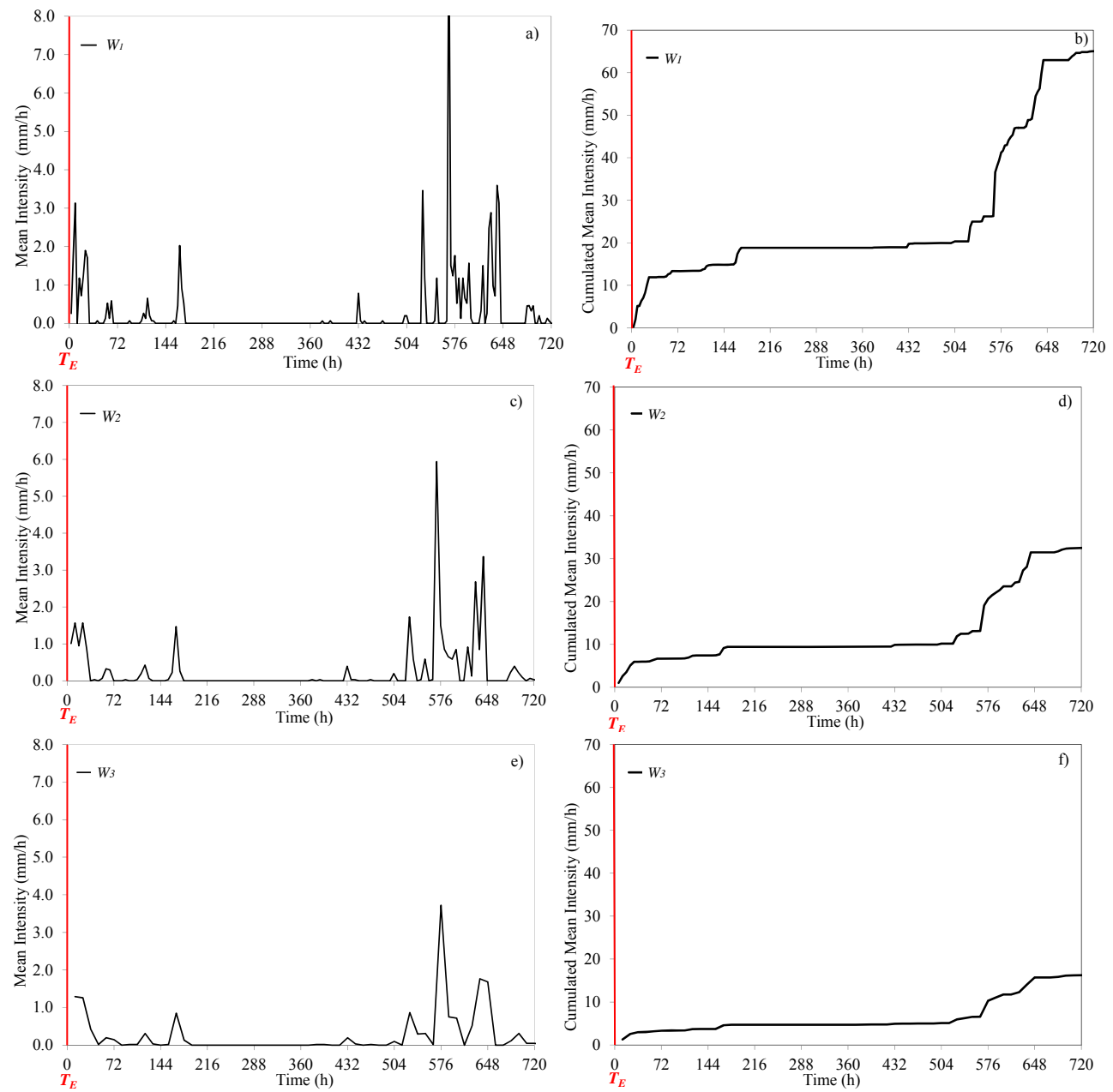

Figure 3. The automated procedure steps 2 and 3 (Fig. 1) are applied to the case study reported in Fig. 2. Starting from the input rainfall record, the time series of the mean intensities (a), (c), and (e), and the cumulated mean intensities (b), (d), and (f) are calculated. These series of 1 month $(720 \mathrm{~h})$ are plotted with the time axis inverted, that is, the time in which 0 coincides with $T_{\mathrm{E}}$. The plots (a) and (b) refer to the time window $W_{1}$; the plots (c) and (d) to $W_{2}$; the plots (e) and (f) to $W_{3}$.

\subsection{Examination of the cumulated rainfall mean intensity series}

Next, in step 4, the procedure explores the three cumulated mean intensity curves: $C_{1}\left\{I\left(W_{1}\right)\right\}, C_{2}\left\{I\left(W_{2}\right)\right\}$, and $C_{3}\left\{I\left(W_{3}\right)\right\}$, starting from $T_{\mathrm{E}}$. It searches for those portions of the curves characterized by negligible rainfall amounts that can reasonably be considered ineffective for the initiation of the landslide. These periods are flat (very low gradient) portions of the cumulated curves. The case of $C_{2}\left\{I\left(W_{2}\right)\right\}$ is illustrated in Fig. 4a. To identify the flat portions, the procedure starts from $T_{1}$ (e.g. $T_{1}=6 \mathrm{~h}$ in the inset of Fig. 4a) and calculates the difference between two cumulated values $\Delta C$ at $T_{i}+\Delta T_{\mathrm{D}}$ and at $T_{i}$, where $T_{i}$ varies between $T_{1}=W_{2}, T_{2}=T_{1}+W_{2} \ldots T_{N}=T_{N-1}+W_{2}$ for $N=112$. In the Fig. $4 \mathrm{a}$ inset, $T_{1}, T_{2} \ldots T_{11}$ are considered for $C_{2}\left\{I\left(W_{2}\right)\right\}$ and $\Delta T_{D}=48 \mathrm{~h}$. Then, the procedure checks whether $\Delta C \leq \varepsilon$, where $\varepsilon$ is the maximum rainfall mean intensity in the period $\Delta T_{\mathrm{D}}$ that can be considered ineffective for the initiation of a landslide. The value of $\varepsilon$ depends on multiple conditions, including the type of landslide, the meteorological and climatic conditions, and the local land use. For the discussion, we use $\varepsilon=0.2 \mathrm{~mm} \mathrm{~h}^{-1}$. This value can be changed by the operator.

If $\Delta C>\varepsilon$, the test is not satisfied, and the procedure is repeated shifting backwards in time $T_{i}=T_{i}+W$, and repeating the calculation. If $\Delta C \leq \varepsilon$, then the corresponding $T_{i}$ is selected and assumed as the approximate start time of the rainfall event $\left(T_{\mathrm{S}}^{*}\right)$. In Fig. $4 \mathrm{~b}, T_{i}=T_{11}=T_{\mathrm{S}}^{*}=66 \mathrm{~h}$.

\subsection{Searching for the actual $T_{\mathrm{S}}$}

To decide which is the actual $T_{\mathrm{S}}$, in step 5 , the procedure goes back to the original hourly rainfall series in the selected time interval $\left[T_{\mathrm{S}}^{*}, T_{\mathrm{E}}\right]$ (as shown in Fig. $4 \mathrm{c}$ ). The actual $T_{\mathrm{S}}$ is 

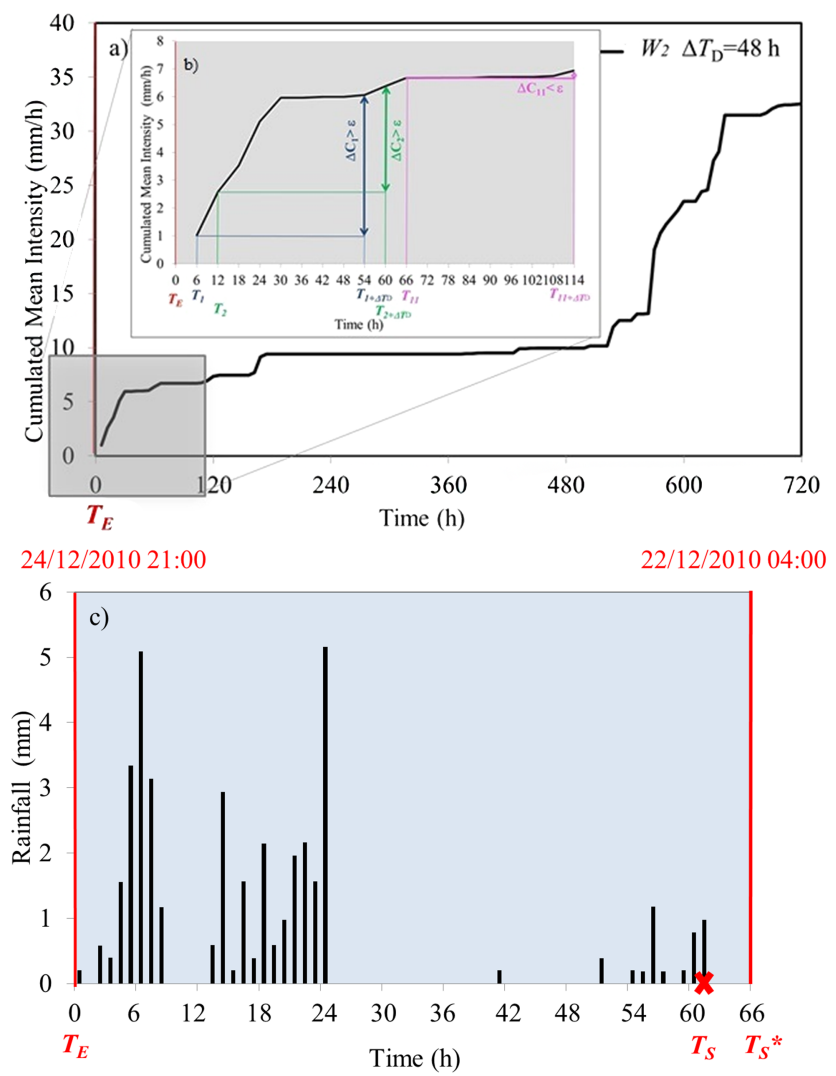

Figure 4. The automated procedure steps 4 and 5 (Fig. 2) are applied to the case study reported in Fig. 2., step 4: (a) the cumulated mean intensity related to the case $W=6 \mathrm{~h}$ and $\Delta T_{\mathrm{D}}$ is analysed to find out the cumulated mean intensity difference $\Delta C<\varepsilon=$ $0.2 \mathrm{~mm} \mathrm{~h}^{-1}$, where a flat trend is detected. (b) The zoom in the cumulated mean intensity shows, in detail, how this difference is calculated between $T_{1} \ldots T_{11}$ and $T_{1+48} \ldots T_{11+48 \mathrm{~h}}$. Step 5: (c) when $T_{\mathrm{S}}^{*}$ is found out, the procedure goes back to the rainfall series and analyses the record portion between $\left[T_{\mathrm{S}}^{*}, T_{\mathrm{E}}\right]$ in order to calculate $T_{\mathrm{S}}$.

taken as the first rainy hour before the $T_{\mathrm{S}}^{*}$. In the example in Fig. $4 \mathrm{c}$, the $T_{\mathrm{S}} *$ is $66 \mathrm{~h}$, but the $T_{\mathrm{S}}$ is identified at $63 \mathrm{~h}$ due to the presence of 3 hours without rain.

Finally, the procedure calculates as the output values the $D$, the $E$, and the $I$ of the identified rainfall event.

\subsection{Software}

The described procedure is implemented in a specific script written for $\mathrm{R}$, the free software environment for statistical computing and graphics (http://www.r-project.org/). The script reads the input rainfall and ancillary data from standard text files, and outputs the results in the form of standard text and Adobe ${ }^{\odot}$ PDF files. The script is independent of the temporal resolution of the rainfall measurement. It is implemented and tested using hourly rainfall data, but it is applicable to sub-hourly data (e.g. rainfall measurements every 5 ,
Table 1. Percentage of landslide events in each Köppen-Geiger climate types (Peel et al., 2007): CS - temperate type with dry summer; $\mathrm{CF}$ - temperate type without dry season; DW - cold type with dry winter.

\begin{tabular}{lc}
\hline$\%$ events & Köppen-Geiger climate types \\
\hline 40 & CF \\
50 & CS \\
10 & DW \\
\hline
\end{tabular}

10,20 , or $30 \mathrm{~min}$ ), to rainfall cumulated over more than 1 hour (e.g. every $2,3,6,12 \mathrm{~h}$ ), or to daily rainfall measurements. The script works with rainfall data cumulated over fixed periods, and cannot be used on the raw data recorded by a rain gauge. Raw records of rainfall measurements consist typically of unevenly spaced sequences of timings when a rainfall measurement was recorded, and can contain spurious or service information (e.g. codes used to report specific errors or malfunctioning conditions). The raw rainfall measurements transmitted by the rain gauge need to be preprocessed before they can be used by the script.

\section{Discussion on possible applications of the automated procedure}

The procedure is applied to automatically reconstruct 100 rainfall events that initiated 100 single landslides in Italy (Fig. 5). These events occurred in different physiographic and geological conditions. Although they cannot be considered representative for all the possible combinations of physiographic characteristic in Italy, they cover the Alps, the Apennines, and the complex settings of Calabria and Sicily, southern Italy. In this specific case, the 100 landslides are extracted from the 2000 pairs relating to the Italian territory, considering different characters of climatic conditions and altitude (see also Tables 1 and 2). This sample, which will be considered as a double blind test on two possible methods to reconstruct the rainfall event responsible for shallow landslide onset, is a small sample from a larger catalogue of more than 2000 rainfall events with landslides compiled by the CNR IRPI research group (Rossi et al., 2012). The 100 landslide events have one common feature: they are single landslides within our catalogue. These single landslide events correspond to the first-known triggering landslide time among the multiple landslide events we collected. Nonetheless, the authors cannot exclude that, for each considered landslide, others happened simultaneously or nearby. Moreover, with respect to the time of unknown possible simultaneous landslides, the authors maintain that the six possible $(D, E)$ pairs derived by the procedure can be representative for the unknown cases relating to the same rain gauge. Then, a discussion on the resulting $100(D, E)$ pairs calculated by the new procedure and the expert method (see Sect. 3) is undertaken. 
Table 2. Percentage of landslide events in six elevation intervals.

\begin{tabular}{lr}
\hline$\%$ events & Elevation interval \\
\hline 34.3 & $<400$ \\
36.3 & $\geq 400<600$ \\
12.7 & $\geq 600<800$ \\
4.9 & $\geq 800<1000$ \\
4.9 & $\geq 1000<1200$ \\
6.9 & $\geq 1200$ \\
\hline
\end{tabular}

The procedure reads the rain gauge measures of rainfall time series resulted in shallow landslides and provides six $(D, E)$ pairs obtained from the combinations of $W\left(W_{1}\right.$, $W_{2}$, and $\left.W_{3}\right)$ and $\Delta T_{\mathrm{D}}$ (48 and $72 \mathrm{~h}$ ). For the 100 considered landslides, the procedure calculates $100(D, E)$ pairs for each combination (black circles), which are compared with the $100(D, E)$ pairs (red squares) obtained from the expert method (Fig. 6a-f). It can be appreciated that, for each landslide, the expert method proposes one rainfall event, whereas the automated procedure calculates six possible rainfall events. The calculated $100(D, E)$ pairs exhibit six mean power-law trends (the best-fit curve resulting from the ordinary least squares) close to the expert mean power-law trend. However, the best agreement between the automated procedure and the expert method is achieved with the combination $W_{2}$ and $\Delta T_{\mathrm{D}}=72 \mathrm{~h}$ (Fig. 6e). Furthermore, it is worth noticing that the six mean power-law trends, obtained using the new procedure, show a slope higher than or equal $\left(W_{2}\right.$ and $\Delta T_{\mathrm{D}}=72 \mathrm{~h}$ ) to that obtained using the expert method. This means that the automated procedure reconstructs more severe rainfall conditions that triggered landslides than the expert method. In other words, the automated method reconstructs longer rainfall events (longer durations) than the expert method. This implies taking into account higher cumulated values. The differences between each 100 pairs from the automated and the expert methods are as high as $40 \%$. From Figs. 6a-f and 7a, it can be appreciated that these differences are not that relevant in terms of mean trends. Considering the data scatters, only a few cumulated values from automated method (Figs. 6d, e, and 7a) are lower than the expert one. Larger samples of pairs are needed to explain these cases.

Figures 7a-b plot a grand total of $600(D, E)$ pairs together with the 100 from the expert method: the two mean power laws keep similar trends. The differences in the two trends are more evident in the log-log graph (Fig. 7a). Figure $7 \mathrm{~b}$ shows the two trends plotted in a semi-logarithmic chart: the difference appears to be very slight and constant in time.

In conclusion, the application to a sample of 100 rainfallinduced landslides shows that the automated procedure enables the reconstruction of multiple $(D, E)$ pairs responsible for the failures. A detailed calibration of the variables used within the procedure is needed to make it applicable to other settings with different climatic conditions.

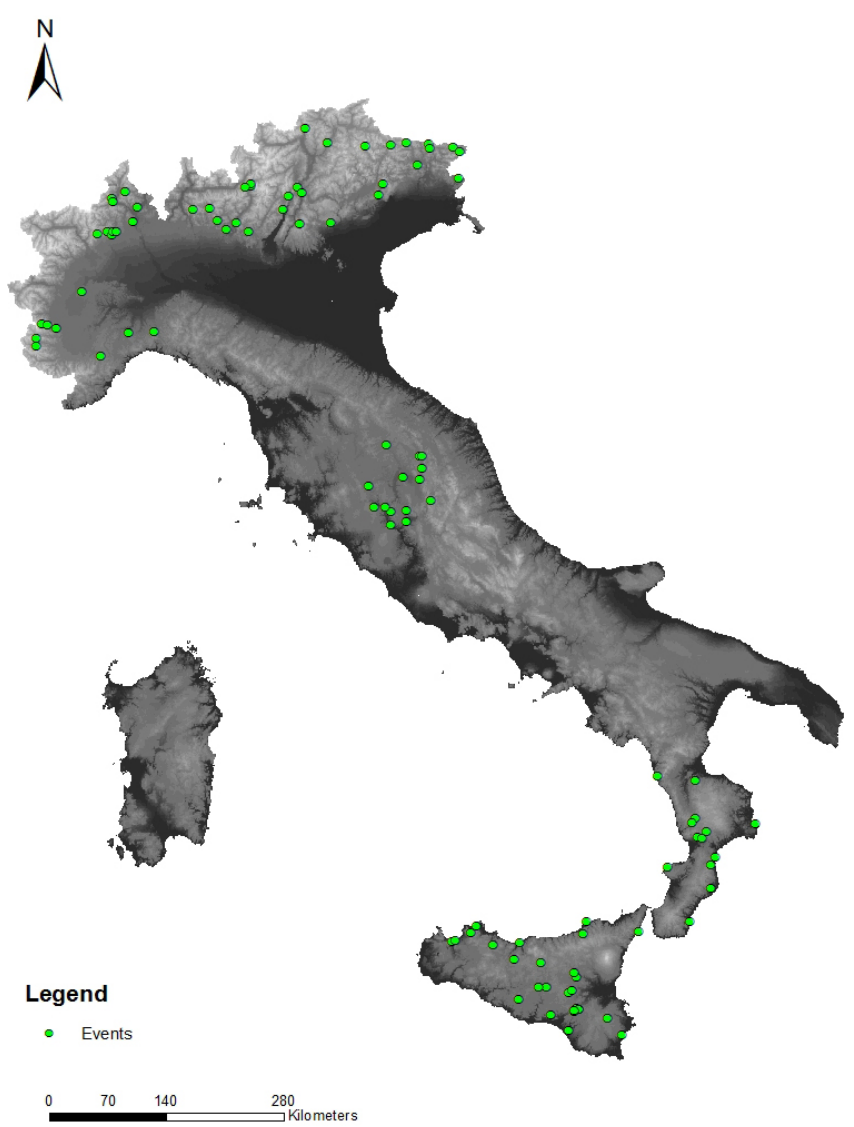

Figure 5. Locations of the 100 shallow landslides considered in this study on the Italian territory over the period 2002-2012.

\section{Final remarks}

The proposed procedure calculates the rainfall conditions responsible for the landslide initiation using measurements from rain gauges. This procedure is among the first attempts to recognize, in the series of rainy periods, objective rules for determining the rainfall conditions $(D, E$ and $I)$ that resulted in landslides. It is based on an algorithm that uses the three variables $\varepsilon, W$, and $\Delta T_{\mathrm{D}}$. These must be calibrated as a function of the local climate and rainfall characters. In the present release, the limitations of this procedure are (1) its empirical bases for the calibration of $\varepsilon$, and (2) its application to a limited number of rainfall events and to narrow territorial extension. The procedure has been applied to a sample of 100 landslides which occurred in Italy in the period from 2002 to 2012, showing results similar to those obtained with the expert method in terms of mean power-law trends. The new procedure therefore seems to be useful in building national or regional empirical rainfall thresholds. However, it shall be further validated on a wider sample of landslides, and on worldwide inventories, as well. 

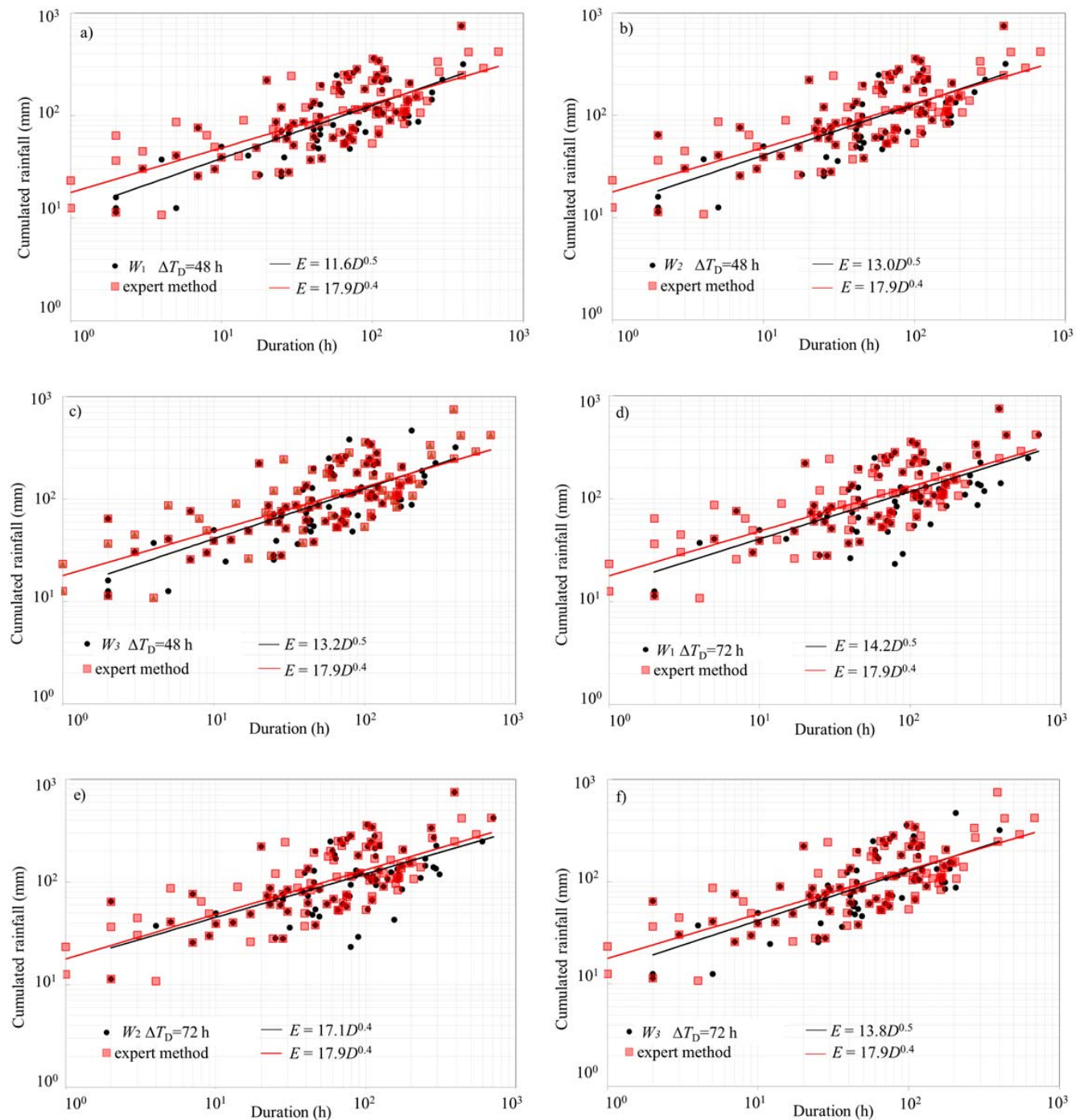

Figure 6. The plots of $100(D, E)$ pairs calculated by the expert method (red square) and the automated procedure (black circle) for six combinations of $W$ and $\Delta T_{\mathrm{D}}$ : (a) $W_{1}$ and $\Delta T_{\mathrm{D}}=48 \mathrm{~h}$; (b) $W_{2}$ and $\Delta T_{\mathrm{D}}=48 \mathrm{~h}$; (c) $W_{3}$ and $\Delta T_{\mathrm{D}}=48 \mathrm{~h} ;$ (d) $W_{1}$ and $\Delta T_{\mathrm{D}}=72 \mathrm{~h}$; (e) $W_{2}$ and $\Delta T_{\mathrm{D}}=72 \mathrm{~h}$; (f) $W_{3}$ and $\Delta T_{\mathrm{D}}=72 \mathrm{~h}$. Black and red lines are the mean trends of the automated and expert procedures, respectively.
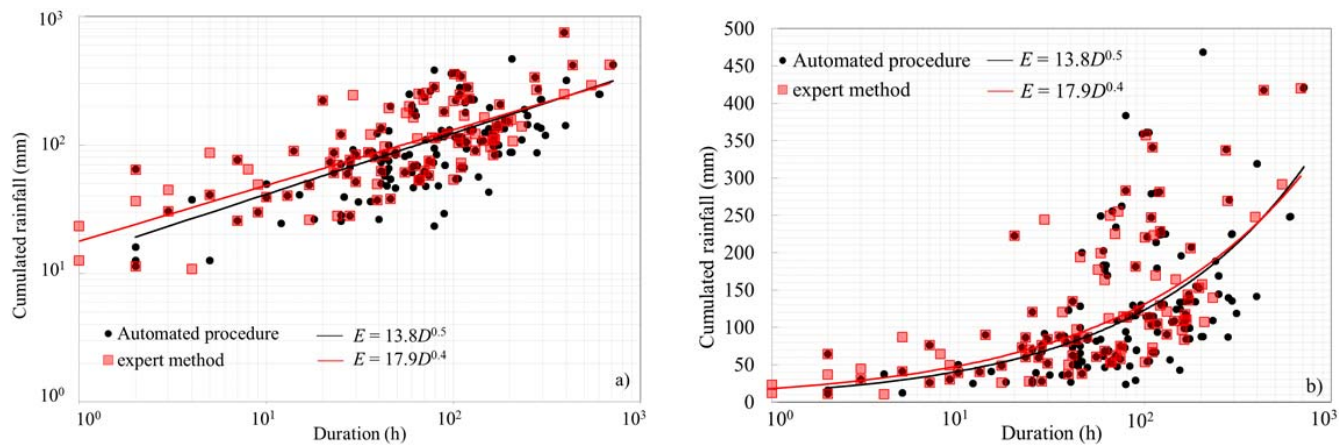

Figure 7. The plots of $(D, E)$ pairs and their mean trend lines (red for the expert method and black for automated procedure) for 100 pairs calculated by the expert method (red square) and 600 pairs by the automated procedure (black circle): (a) log-log graph; (b) semi-logarithmic chart. 
Acknowledgements. This work was supported by the Italian National Department for Civil Protection. Carmela Vennari is supported by a grant of the Italian National Department for Civil Protection.

Edited by: T. Glade

Reviewed by: three anonymous referees

\section{References}

Aleotti, P.: A warning system for rainfall-induced shallow failures, Eng. Geol., 73, 247-265, 2004.

Brand, E. W., Premchitt, J., and Phillipson, H. B.: Relationship between rainfall and landslides in Hong Kong, Proc. 4th Int. Symp. on Landslides, Toronto, 1, 377-384, 1984.

Brunetti, M. T., Peruccacci, S., Rossi, M., Luciani, S., Valigi, D., and Guzzetti, F.: Rainfall thresholds for the possible occurrence of landslides in Italy, Nat. Hazards Earth Syst. Sci., 10, 447-458, doi:10.5194/nhess-10-447-2010, 2010.

Caine, N.: The rainfall intensity-duration control of shallow landslides and debris flows, Geograf. Annal, 62A, 23-27, 1980.

Calcaterra, D., Parise, M., Palma, B., and Pelella, L.: The influence of meteoric events in triggering shallow landslides in pyroclastic deposits of Campania, Italy, in: Landslides in research, theory and practice, edited by: Bromhead, E., Dixon, N., and Ibsen, M. L., Proc. 8th International Symposium on Landslides, Cardiff, 1, 209-214, 2000.

Campbell, R. H.: Debris flow originating from soil slip during rainstorm in southern California, Q. Eng. Geol., 7, 339-349, 1975.

Cannon, S. H. and Gartner, J. E.: Wildfire-related debris flows from a hazards perspective, in: Debris flow hazards and related phenomena, edited by: Jakob, M. and Hungr, O., Berlin, Heidelberg: Springer, 363-385, 2005.

Cardinali, M., Galli, M., Guzzetti, F., Ardizzone, F., Reichenbach, P., and Bartoccini, P.: Rainfall induced landslides in December 2004 in south-western Umbria, central Italy: types, extent, damage and risk assessment, Nat. Hazards Earth Syst. Sci., 6, 237260, doi:10.5194/nhess-6-237-2006, 2006.

Crosta, G. B. and Frattini, P.: Rainfall thresholds for triggering soil slips and debris flow, in: Proc. of the 2nd EGS Plinius Conference on Mediterranean Storms, Siena, Italy, 2000.

De Vita, P. and Reichenbach, P.: Rainfall-triggered landslides: a reference list, Environ. Geol., 35, 219-233, 1998.

Gariano, S. L., Iovine, G., Brunetti M. T., Peruccacci, S., Luciani S., Bartolini D., Palladino, M., Vessia, G., Viero, A., Vennari, C., Antronico, L., Deganutti, A. M., Luino, F., Parise, M., Terranova, O. G., and Guzzetti, F.: Populating a catalogue of rainfall events that triggered shallow landslides in Italy, Rendiconti Online della Società Geologica Italiana, 21, 396-398, 2012.

Glade, T., Crozier, M., and Smith, P.: Applying probability determination to refine landslide-triggering rainfall thresholds using empirical "antecedent daily rainfall model", Pure Appl. Geophys., 157, 1059-1079, 2000.

Govi, M., Mortara, G,. and Sorzana, P.: Eventi idrologici e frane, Geol. Appl. Idrogeol., 20, 359-375, 1985.
Guzzetti, F.: Hydrological triggers of diffused landsliding, Environ. Geol., 35, 79-80, 1998.

Guzzetti, F., Cardinali, M., Reichenbach, P., Cipolla, F., Sebastini, C., Galli, M., and Salvati, P.: Landslides triggered by the 23 November 2000 rainfall event in the Imperia Province, Western Liguria, Italy, Eng. Geol., 73, 229-245, 2004.

Guzzetti, F., Peruccacci, S., Rossi, M., and Stark, C.P.: Rainfall thresholds for the initiation of landslides in central and southern Europe, Meteorol. Atmos. Phys., 98, 239-267, 2007.

Guzzetti, F., Peruccacci, S., Rossi, M., and Stark, C. P.: The rainfall intensity-duration control of shallow landslides and debris flows: an update, Landslides, 5, 3-17, 2008.

Hong, Y., Adler, R. F., and Huffman, G. J.: Evaluation of the potential of NASA multi-satellite precipitation analysis in global landslide hazard assessment, Geophys. Res. Lett., 33, L22402, doi:10.1029/2006GL028010, 2006.

Innes, J. L.: Debris flows, Prog. Phys. Geogr., 7, 469-501, 1983.

Kirschbaum, D. B., Adler, R., Hong, Y., and Lerner-Lam, A.: Evaluation of a preliminary satellite-based landslide hazard algorithm using global landslide inventories, Nat. Hazards Earth Syst. Sci., 9, 673-686, doi:10.5194/nhess-9-673-2009, 2009.

Larsen, M. C. and Simon, A.: A rainfall intensity-duration threshold for landslides in a humid-tropical environment, Puerto Rico, Geogr. Ann. A., 75, 13-23, 1993.

Lumb, P.: Slope failure in Hong Kong, Q. J. Eng. Geol., 8, 31-65, 1975.

Melillo, M., Brunetti, M. T., Peruccacci, S., Gariano, S., and Guzzetti, F.: An algorithm for the objective reconstruction of rainfall events responsible for landslides, Landslides, doi:10.1007/s10346-014-0471-3, online first, 2014.

$\mathrm{Ng}, \mathrm{C} . \mathrm{W}$. W. and Shi, Q.: Influence of rainfall intensity and duration on slope stability in unsaturated soils, Q. J. Eng. Geol., 31, 105113, 1998.

Nilsen, T. H., Taylor, F. A., and Brabb, E. E.: Recent landslides in Alameda County, California (1940-71): an estimate of economic losses and correlation with slope, rainfall and ancient landslide deposits, US Geol. Surv. Bull., 1398, 21 pp., 1976.

Oberstelehn, D.: Slope stability of the Lomerias Muertas area, San Benito County, California, PhD, Stanford University, California, 1976.

Onodera, T., Yoshinaka, R., and Kazama, H.: Slope failures caused by heavy rainfall in Japan, in: Proc. 2nd Congr. Int. Assoc. Eng. Geologists, Sao Paolo, 2, V11.1-V11.10, 1974.

Pasuto, A. and Silvano, S.: Rainfall as a trigger of shallow mass movements. A case study in the Dolomites, Italy, Environ. Geol., 35, 184-189, 1998.

Peel, M. C., Finlayson, B. L., and McMahon, T. A.: Updated world map of the Köppen-Geiger climate classification, Hydrol. Earth Syst. Sci., 11, 1633-1644, doi:10.5194/hess-11-16332007, 2007.

Peruccacci, S., Brunetti, M. T., Luciani, S., Vennari, C., and Guzzetti, F.: Lithological and seasonal control on rainfall thresholds for the possible initiation of landslides in central Italy, Geomorphology, 139-140, 79-90, 2012.

Rahardjo, H., Li, X. W., Toll, D. G., and Leong, E. C.: The effect of antecedent rainfall on slope stability, Geotech. Geoenvironm. Eng., 19, 371-399, 2001. 
Rossi, M., Peruccacci, S., Brunetti, M. T., Marchesini, I., Luciani, S., Ardizzone, F., Balducci, V., Bianchi, C., Cardinali, M., Fiorucci, F., Mondini, A. C., Reichenbach, P., Salvati, P., Santangelo, M., Bartolini, D., Gariano, S. L., Palladino, M., Vessia, G., Viero, A., Antronico, L., Borselli, L., Deganutti, A. M., Iovine, G., Luino, F., Parise, M., Polemio, M., and Guzzetti, F.: SANF: a national warning system for rainfall-induced landslides in Italy, in: Proceedings of the 11th International Conference and 2nd North American symposium on landslides, Banff, Alberta, Canada, 3-8 June, 2012.

Vennari, C., Gariano, S. L., Antronico, L., Brunetti, M. T., Iovine, G., Peruccacci, S., Terranova, O., and Guzzetti, F.: Rainfall thresholds for shallow landslide occurrence in Calabria, southern Italy, Nat. Hazards Earth Syst. Sci., 14, 317-330, doi:10.5194/nhess-14-317-2014, 2014.
Wieczorek, G. F. and Guzzetti, F.: A review of rainfall thresholds tor triggering landslides, in: Mediterranean Storms, Proceedings Plinius Conference '99, Maratea, 14-16 October 1999, GNDCI pub. no. 2012, edited by: Claps P. and Siccardi F., Editoriale Bios, Cosenza, 407-414, 2000.

Wilson, R. C. and Wieczorek, G. F.: Rainfall thresholds for the initiation of debris flow at La Honda, California, Environ. Eng. Geosci., 1, 11-27, 1995. 